\title{
Optimising power grids using batteries and fuzzy control of photovoltaic generation
}

Tobias Lühn Dr. rer. pol.

Research Assistant, Chair of Production and Logistics, Faculty of Economics Sciences, Georg-August-University of Göttingen, Göttingen, Germany (corresponding author: tobias.luehn@wiwi.uni-goettingen.de) (Orcid:0000-0003-0502-4987)
Jutta Geldermann Dr. rer. pol. habil.

Professor, Chair of Production and Logistics, Faculty of Economics Sciences, Georg-August-University of Göttingen, Göttingen, Germany (Orcid:0000-0002-6437-0305)

Germany's energy turnaround is leading towards an increasing integration of photovoltaics throughout its distribution grid. As solar power generation fluctuates greatly, distribution system operators are faced with the challenge of preventing grid component overload and voltage range violations. One solution might be to integrate battery storage systems into private households and reduce active peak power at the grid connection point. Since peak shaving is often impossible with the conventional operating strategy of the storage system, solar plants must sometimes be throttled back. In this study, a fuzzy control system is introduced that reduces peak feed-in and thus also energy losses due to throttling back solar power. The system uses solar surplus and battery charge level as input parameters, and standardises them to ensure easy adjustment to different combinations of plant size and storage capacity. Load flows for a complete year were modelled using real-world measurement data, which showed that even small electrical storage capacities $(<5 \mathrm{kWh}$ ) reduce energy losses considerably and produce only small losses in self-consumption. Thus, there is an economic benefit for plant operators which switch from a conventional to a grid-optimised operating strategy.

\section{Notation \\ $C_{\mathrm{CO}} \quad$ annual profit (conventional operating strategy) \\ $C_{\mathrm{GO}} \quad$ annual profit (grid-optimised operating strategy) \\ $C_{\mathrm{PU}, \mathrm{CO}}$ annual costs for electricity purchase (conventional operating strategy) \\ $C_{\mathrm{PU}, \mathrm{GO}}$ annual costs for electricity purchase (grid-optimised operating strategy) \\ $C_{\mathrm{RE}, \mathrm{CO}}$ annual revenues from selling energy (conventional operating strategy) \\ $C_{\mathrm{RE}, \mathrm{GO}}$ annual revenues from selling energy (grid-optimised operating strategy) \\ $E_{\mathrm{LG}, \mathrm{CO}}$ annual amount of energy purchased from the grid (conventional operating strategy) \\ $E_{\mathrm{LG}, \mathrm{GO}}$ annual amount of energy purchased from the grid (conventional operating strategy) \\ $E_{\mathrm{PV}, \mathrm{CO}} \quad$ annual amount of energy fed into the grid (conventional operating strategy) \\ $E_{\mathrm{PV}, \mathrm{GO}} \quad$ annual amount of energy fed into the grid (grid-optimised operating strategy) \\ $p_{\mathrm{PV}} \quad$ photovoltaic feed-in tariff \\ $p_{\mathrm{RP}} \quad$ retail electricity price}

\section{Introduction}

The German government intends to increase the share of renewable energies for power generation to $40-45 \%$ by 2025 (BMWi, 2014: section 1, paragraph 2) and, indeed, the installed peak power of photovoltaic (PV) plants has increased from $1 \mathrm{GW}_{\mathrm{p}}$ in 2004 to more than $40 \mathrm{GW}_{\mathrm{p}}$ in 2016 (BMWi,
2017). The power output of PVs fluctuates greatly due to changing weather conditions and natural solar cycles. Thus, distribution system operators face two major challenges: preventing the overload of grid components and keeping the voltage range within the constraints specified in the standard DIN EN 50160 (DIN, 2010; Lühn et al., 2014).

One way to meet these challenges is to limit the maximum grid feed-in and throttle back PV power in times of high PV generation. With a feed-in limitation, the inverter dynamically adjusts the PV power production to ensure that the feed-in power does not exceed a preconfigured threshold. Therefore, a smart meter must be installed at the site that measures feed-in or power consumption. In times of high solar radiation, the PV power is reduced by modifying the maximum power point tracking (MPPT). MPPT algorithms are required to maximise the PV power due to the non-linear voltage-current characteristic of a solar panel control. This approach results in high energy losses. To evaluate the annual operating results, the authors performed simulations for an entire year and for various system configurations. The combination of different PV plant sizes and battery storage capacities results in various system configurations.

Local battery storage systems could reduce such losses when the PV generation exceeding the feed-in limitation are stored in the battery. However, the conventional operating strategy for battery storage only aims to maximise PV self-consumption and not to reduce the maximum grid feed-in. In contrast, gridoptimised operating strategies reduce peak feed-in and thus 
also PV curtailment losses. To prevent the feed-in power from exceeding the feed-in threshold, the grid-optimised operating strategies need to ensure that enough battery storage capacity is available at noon to absorb production that exceeds the feedin limit. In all previously developed grid-optimised operating strategies (e.g. Appen et al., 2014; Lödl et al., 2011; Weniger et al., 2014; Williams et al., 2013), however, solar forecasts with a high time resolution are required, which makes their operating behaviour strongly dependent on forecast quality. In this paper, the authors present a grid-optimised operating strategy that uses a fuzzy logic controller (FLC). Unlike the existing grid-optimised operating strategies, the FLC is rule based and does not need solar forecast data.

\section{Simulation model}

Fuzzy-set-based models are useful for handling inherent uncertainty and imprecision in operational research problems (Herrera and Verdegay, 1997). Fuzzy control has also been applied and tested in recent years for energy (Kyriakarakos et al., 2012). The FLC presented here uses the solar power surplus and battery charge level as input parameters. Unlike the existing grid-optimised operating strategies, detailed solar forecasts are not required. On days with high solar forecasts, the FLC is used; on days with low solar forecast, the conventional operating strategy is used, which ensures a high level of PV self-consumption.

The authors performed simulations based on the measured time series of power consumption and PV power output of a household located in northern Germany with a time resolution of $1 \mathrm{~min}$. The peak power of the PV plant is $10 \mathrm{~kW}_{\mathrm{p}}$ and the annual energy yield for 2014 is $10200 \mathrm{kWh}$.

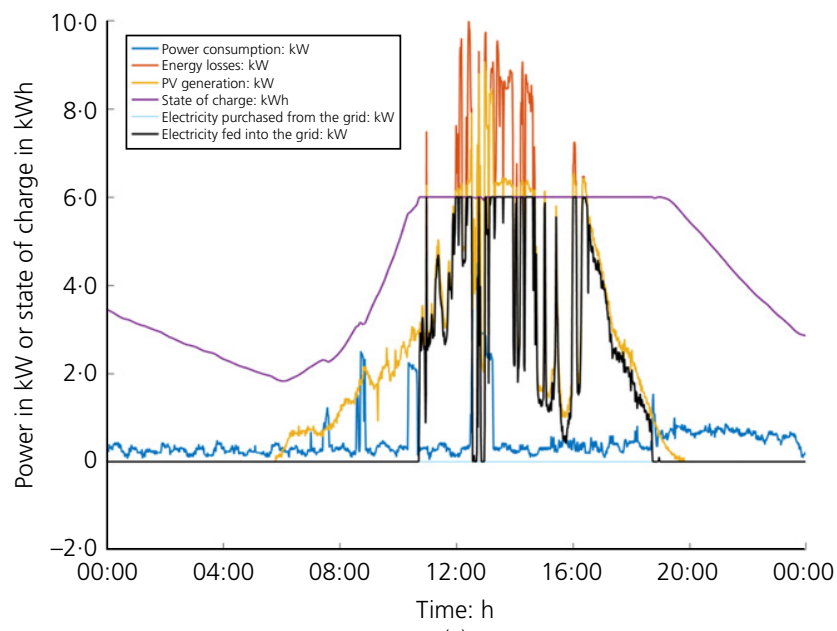

(a)
The household has an annual power consumption of $3700 \mathrm{kWh}$, which is typical for a German three-person household. The PV home storage system is assumed to be an AC-coupled, lithium-ion battery with a usable storage capacity of $6 \mathrm{kWh}$ and a round-trip efficiency of $88 \%$. According to regulatory requirements, the feed-in limit at the grid connection point is set to $0.6 \mathrm{~kW} / \mathrm{kW}_{\mathrm{p}}$. Feed-in power exceeding this threshold is throttled.

\section{Energetic assessment}

The only objective of the conventional operating strategy is to increase self-consumption of the household and thus lower the amount of electricity that must be purchased. This is achieved by storing the solar surplus during the daytime and using it to supply loads in the evening and during the night. Power exchange between the battery storage system and the grid is not possible. The conventional operating strategy immediately starts charging the battery when the PV production exceeds the power consumption of the household (Figure 1(a)). On days with high insolation, the battery is fully charged before noon. Therefore, the peak power production cannot be stored in the battery storage and the PV plant must be throttled back to comply with the feed-in limitation. On an example sunny day shown in Figure 2, the energy losses through throttling are $3 \cdot 0 \mathrm{kWh}$.

The grid-optimised operating strategy reduces the energy losses from 3.0 to $0.3 \mathrm{kWh}$. To prevent the feed-in power from exceeding the threshold $\left(0 \cdot 6 \mathrm{~kW} / \mathrm{kW}_{\mathrm{p}}\right)$, enough storage capacity must be available at noon to absorb the production that exceeds the feed-in limitation. Two main measures ensure that the storage is not fully charged at noon (Figure 1(b)). First,

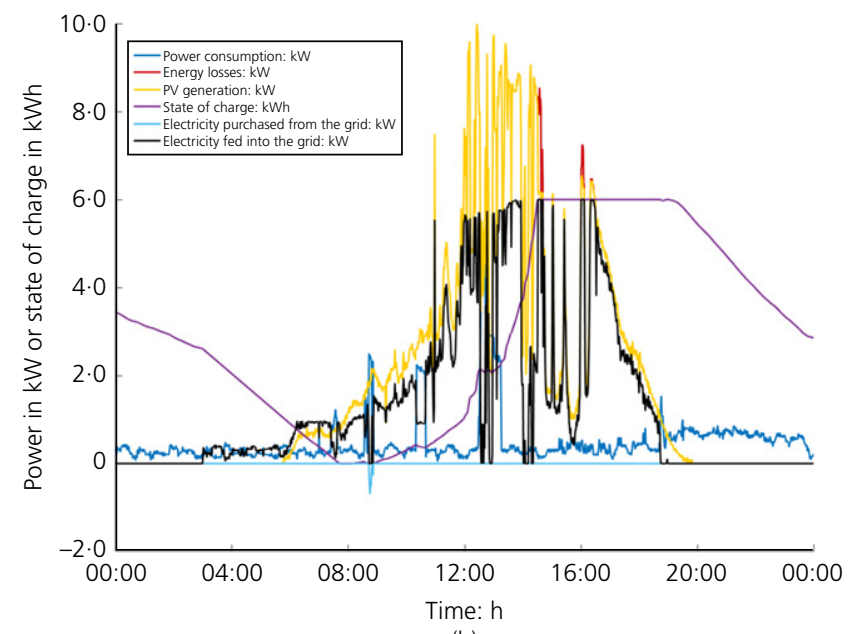

(b)

Figure 1. Energy flows on an example sunny day based on the conventional (a) and the grid-optimised operating strategy (b). A fullcolour version of this figure can be found on the ICE Virtual Library (www.icevirtuallibrary.com) 


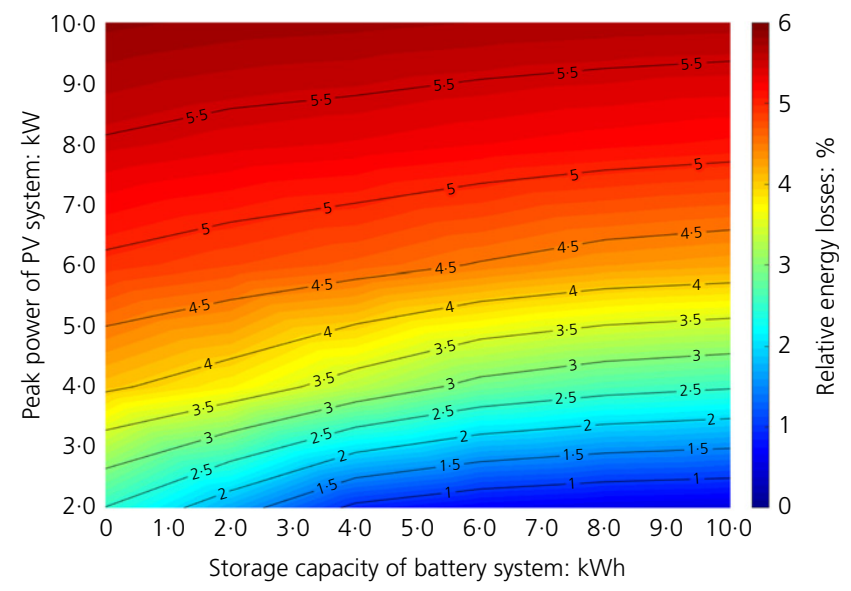

(a)

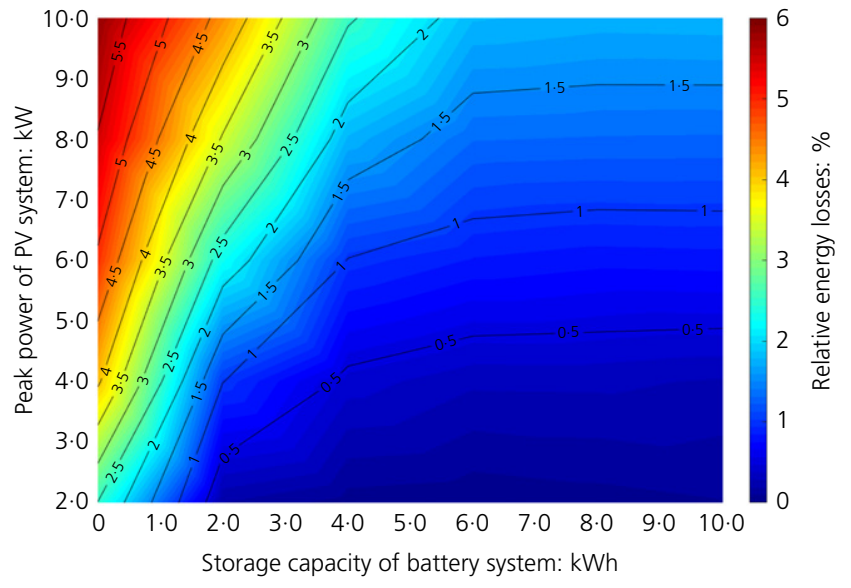

(b)

Figure 2. Relative energy losses due to the feed-in limitation $(0.6 \mathrm{~kW} / \mathrm{kW})$ for the conventional operating strategy (a) and the grid-optimised operating strategy (b). A full-colour version of this figure can be found on the ICE Virtual Library (www.icevirtuallibrary.com)

the battery storage is discharged to the low-voltage grid overnight, in order to begin the day with an empty battery. Second, the battery storage is only charged with part of the PV surplus in the morning hours. The remainder is fed directly into the grid. These two measures ensure that a larger portion of the storage capacity is available at noon to store the PV surplus that exceeds the threshold.

To evaluate the annual operating results, the authors performed simulations for an entire year and for various system configurations. The combination of different PV plant sizes and battery storage capacities results in various system configurations. For each system configuration, the relative energy losses are calculated as the ratio between the throttled PV energy and the total PV generation. The relative energy losses decrease with a smaller peak power of the PV plant and a bigger storage capacity of the battery system (Figure 2). Up to $6 \%$ of the annual PV generation must be throttled when installing large PV plants $\left(\gg 8 \mathrm{~kW}_{\mathrm{p}}\right.$ ) without battery storage systems. Using the conventional operating strategy, the relative energy losses can only be slightly reduced by integrating battery storage systems. The grid-optimised operating strategy, however, allows energy losses to be reduced significantly. To reach good results, the ratio between the peak power of the PV plant and the storage capacity of the battery system must be lower than $3 \mathrm{~kW}_{\mathrm{p}} / \mathrm{kWh}$ for PV plants with a peak power of up to $10 \mathrm{~kW}_{\mathrm{p}}$. Other gridoptimised operating strategies such as those of de May and Simoens (1981), Lödl et al. (2011) and Weniger et al. (2014) take real forecast data on PV power into account to improve the optimisation. However, these operating strategies strongly depend on the data quality and are complex to implement.
The grid-optimised operating strategy reduces the energy losses from throttling, but increases the annual energy exchange from and to the grid in two ways. First, it may lead to free storage capacity in the afternoon and, second, it may lead to an empty battery in the morning. Depending on the system configuration, the additional annual energy purchase from the grid is between 30 and $300 \mathrm{kWh}$. In addition, the grid-optimised operating strategy increases the annual energy fed into the grid by preventing energy losses. Depending on the system configuration, the additional annual energy fed into the grid is between 180 and $480 \mathrm{kWh}$.

\section{Economic assessment}

In Germany, plant operators receive a fixed feed-in tariff of $0 \cdot 123 €$ for each kilowatt-hour fed into the grid and pay $0 \cdot 278 €$ for each kilowatt-hour purchased from the grid (as of April 2016) (BMWi, 2015; Verivox GmbH, 2017). As electricity prices for private households have increased and PV feed-in tariffs have decreased in recent years, the selfconsumption of PV power has become more and more attractive. To compare the economics of the conventional and the grid-optimised operating strategy, the authors performed a cost-benefit analysis concerning the cash flows, $C$, due to the energy exchange from and to the grid.

The annual revenues, $C_{\mathrm{RE}}$, from selling energy are calculated using the PV feed-in tariff, $p_{\mathrm{PV}}=0 \cdot 123 € / \mathrm{kWh}$, and the annual amount of energy fed into the grid, $E_{\mathrm{PV}}$. The annual costs for the electricity purchase, $C_{\mathrm{PU}}$, are obtained from the retail electricity price, $p_{\mathrm{RP}}=0.278 € / \mathrm{kWh}$, and the annual amount of 


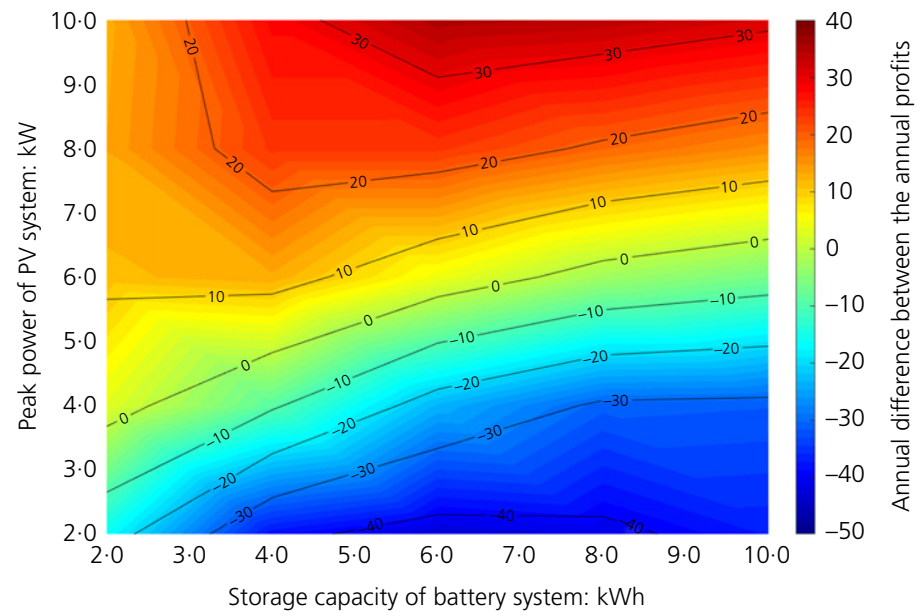

(b)

Figure 3. (a) Purchase costs and feed-in remuneration of the exemplary household with a $10 \mathrm{~kW}$ PV system and a 6 kWh battery storage system using the conventional operating strategy and the grid-optimised operating strategy. (b) Difference between the annual profits of the conventional and the grid-optimised operating strategy. A full-colour version of this figure can be found on the ICE Virtual Library (www.icevirtuallibrary.com)

energy purchased from the grid, $E_{\mathrm{LG}}$ (Figure 3(a)). The index $\mathrm{CO}$ of the variables stands for the conventional operating strategy, whereas GO stands for the grid-optimised operating strategy. Therefore, the annual profit of the conventional operating strategy is labelled as $C_{\mathrm{CO}}$ and the annual profit of the grid-optimised operating strategy is labelled as $C_{\mathrm{GO}}$.

$$
C_{\mathrm{CO}}=C_{\mathrm{RE}, \mathrm{CO}}-C_{\mathrm{PU}, \mathrm{CO}}=\left(E_{\mathrm{PV}, \mathrm{CO}} p_{\mathrm{PV}}\right)-\left(E_{\mathrm{LG}, \mathrm{CO}} p_{\mathrm{RP}}\right)
$$

$$
C_{\mathrm{GO}}=C_{\mathrm{RE}, \mathrm{GO}}-C_{\mathrm{PU}, \mathrm{GO}}=\left(E_{\mathrm{PV}, \mathrm{GO}} p_{\mathrm{PV}}\right)-\left(E_{\mathrm{LG}, \mathrm{GO}} p_{\mathrm{RP}}\right)
$$

To compare the two operating strategies, the difference between the annual profits is calculated at $C_{\mathrm{GO}}-C_{\mathrm{CO}}=€ 35$. The additional income generated by the grid-optimised operating strategy is strongly influenced by the size of the PV plant (Figure 3(b)). Greater revenues can be obtained with larger PV plants, whereas financial losses occur with small PV plants. Furthermore, reducing energy losses with the grid-optimised operating strategy is only beneficial when the grid feed-in is sufficiently remunerated. It is expected that future PV feed-in tariffs will continue to decrease and the retail electricity price will continue to increase, thus reducing the benefits of gridoptimised operating strategies.

\section{Conclusions}

The authors have developed a grid-optimised operating strategy for battery storage systems using an FLC. The gridoptimised operating strategy reduces the energy losses resulting from throttling significantly compared with the conventional operating strategy. For this purpose, the ratio between the peak power of the PV plant and the storage capacity of the battery system must be lower than $3 \mathrm{~kW}_{\mathrm{p}} / \mathrm{kWh}$. The gridoptimised operating strategy can increase the profitability of large, roof-mounted PV plants and, at the same time, increase the hosting capacity of low-voltage grids for future PV expansion.

\section{Acknowledgements}

The authors acknowledge J. Schmiesing and B. Lehde for their support and help in the e-home energy project 2020. The project was funded by Avacon AG and the Energy Research Centre of Lower Saxony (EFZN) (project duration: July 2011 to June 2016).

\section{REFERENCES}

Appen Jv, Stetz T, Idlbi B and Braun M (2014) Enabling high amounts of PV systems in low voltage grids using storage systems. In 29th European Photovoltaic Solar Energy Conference and Exhibition (EU PVSEC 2014) (Bokhoven TP, Jäger-Waldau A and Helm P (eds)). WIP Wirtschaft und Infrastruktur GmbH \& Co Planungs-KG, München, Germany, pp. 2380-2386.

BMWi (Federal Ministry for Economic Affairs and Energy) (2014) Erneuerbare-Energien-Gesetz (Act on the Development of Renewable Energy Sources (Renewable Energy Sources Act - RES Act 2014)). BMWi, Berlin, Germany.

BMWi (2015) Zahlen und Fakten Energiedaten - National und international Entwicklungen. BMWi, Berlin, Germany. See http:/www.bmwi.de/DE/Themen/Energie/energiedaten.html (accessed 09/08/2017) (in German). 
Optimising power grids using batteries

and fuzzy control of photovoltaic

generation

Lühn and Geldermann
BMWi (2017) Zeitreihen zur Entwicklung der erneuerbaren Energien in Deutschland. BMWi, Berlin, Germany. See http://www. erneuerbare-energien.de/EE/Navigation/DE/Service/Erneuerbare_ Energien_in_Zahlen/Zeitreihen/zeitreihen.html (accessed 09/08/2017) (in German).

de Mey G and Simoens H (1981) Coupling between a photovoltaic panel and the power grid with battery storage. Electric Power Systems Research 4(4): 283-288.

DIN (Deutsches Institut für Normung) (2010) DIN EN 50160:2010: Voltage characteristics of electricity supplied by public electricity networks. DIN, Berlin, Germany.

Herrera F and Verdegay JL (1997) Fuzzy sets and operations research: perspectives. Fuzzy Sets and Systems 90(2): 207-218.

Kyriakarakos G, Dounis Al, Arvanitis KG and Papadakis G (2012) A fuzzy logic energy management system for polygeneration microgrids. Renewable Energy 41: 315-327.

Lödl M, Witzmann R and Metzger M (2011) Operation strategies of energy storages with forecast methods in low-voltage grids with a high degree of decentralized generation. In 2011 IEEE Electrcial Power and Energy Conference. IEEE, Piscataway, NJ, USA, pp. 52-56.
Lühn T, Schlömer G, Schmidtmann G et al. (2014) Multi-criteria analysis of grid expansion concepts on the low voltage level. Zeitschrift für Energiewirtschaft 38(3): 183-200.

Verivox GmbH (2017) Strompreiszusammensetzung 2017. Verivox, Heidelberg, Germany. See http://www.verivox.de/themen/ strompreiszusammensetzung/ (accessed 09/08/2017) (in German).

Weniger J, Bergner J and Quaschning V (2014) Integration of PV power and load forecasts into the operation of residential PV battery systems. In Proceedings of the 4th Solar Integration Workshop (Betancourt U and Ackermann T (eds)). Energynautics GmbH, Darmstadt, Germany, pp. 379-386. See https://pvspeicher.htwberlin.de/wp-content/uploads/2014/04/SIW-2014-Integration-ofPV-power-and-load-forecasts-into-the-operation-of-residential-PVbattery-systems.pdf (accessed 10/28/2015).

Williams C, Binder J, Danzer M, Sehnke F and Felder M (2013) Battery charge control schemes for increased grid compatibility of decentralized PV systems. In Proceedings of the 28th European Photovoltaic Solar Energy Conference and Exhibition (Mine A, Jäger-Waldau A and Helm P (eds)). WIP Wirtschaft und Infrastruktur GmbH \& Co Planungs KG, München, Germany, pp. 3751-3756.

\section{How can you contribute?}

To discuss this paper, please email up to 500 words to the editor at journals@ice.org.uk. Your contribution will be forwarded to the author(s) for a reply and, if considered appropriate by the editorial board, it will be published as discussion in a future issue of the journal.

Proceedings journals rely entirely on contributions from the civil engineering profession (and allied disciplines). Information about how to submit your paper online is available at www.icevirtuallibrary.com/page/authors, where you will also find detailed author guidelines. 